\title{
Gene therapy for HIV infections: Intracellular immunization
}

\author{
Alain Piché MD
}

\begin{abstract}
A Piché. Gene therapy for HIV infections: Intracellular immunization. Can J Infect Dis 1999;10(4):307-312.
Despite significant advances in the treatment of human immunodeficiency virus (HIV) infection in the past 10 years, it remains an incurable disease. The inability of traditional drug-based therapies to inhibit HIV replication effectively for extended periods of time has stimulated intense research to develop novel approaches for this disease. Current understanding of HIV molecular biology and pathogenesis has opened the way for the development of gene therapy strategies for HIV infections. In this context, a number of intracellular immunization-based strategies have been evaluated, and some of them have reached the stage of phase I/II human clinical trials. These strategies include the use of single-chain antibodies, capsid-targeted viral inactivation, transdominant negative mutants, ribozymes, antisense oligonucleotides and RNA decoys. While a number of issues remain to be studied before intracellular immunization can be applied to the treatment of HIV infections, the significant progress already made in this field is likely to lead to clinical applications.
\end{abstract}

Key Words: Gene therapy; Human immunodeficiency virus (HIV); Intracellular immunization

\section{Thérapie génique pour les infections au VIH : immunisation intracellulaire}

RÉSUMÉ : Malgré les grands progrès réalisés dans le traitement de l'infection au virus de l'immunodéficience humaine (VIH) depuis les dix dernières années, cette maladie reste incurable. L'impuissance des traitements médicamenteux classiques à inhiber efficacement la réplication du VIH pendant des périodes prolongées a stimulé une recherche intense en vue de mettre au point de nouvelles approches pour cette maladie. Les connaissances actuelles sur la biologie moléculaire et la pathogenèse du VIH ont pavé la voie à des stratégies de thérapie génique pour les infections au VIH. Dans ce contexte, un certain nombre de stratégies fondées sur l'immunisation intracellulaire ont été évaluées et certaines d'entre elles ont atteint le stade des essais cliniques de phase I/II chez l'être humain. Ces stratégies sont, notamment, l'emploi des anticorps monocaténaires, l'inactivation virale axée sur la capside, les mutants négatifs transdominants, les ribozymes, les oligonucléotides antisens et les leurres d'ARN. Si un certain nombre de questions restent à explorer avant que l'on puisse appliquer une immunisation intracellulaire au traitement des infections au VIH, les importants progrès faits à ce jour dans ce domaine risquent fort de mener à des applications cliniques.

$\mathrm{G}$ ene therapy is defined as the genetic modification of somatic cells to correct a disease phenotype or to achieve a therapeutic benefit. Gene therapy is still in its formative stage, being investigated mostly in basic research laboratories. Nevertheless, in the past few years, a number of human clinical trials have been initiated to test important concepts. Preliminary data emerging from these initial trials suggest that gene therapy is a safe approach. Hundreds of patients have been treated in these trials with no reports of major side effects. The rationale for human gene therapy lies in the recent delineation

Département de Microbiologie, Université de Sherbrooke, Sherbrooke, Québec

Correspondence and reprints: Dr Alain Piché, Département de Microbiologie et Infectiologie, Faculté de Médecine, Université de Sherbrooke, 3001, 12ième Avenue Nord, Sherbooke, Québec J1H 5N4. Telephone 819-564-5321, fax 819-564-5392, e-mail alain.piche@courrier.usherb.ca 
TABLE 1

Gene therapy clinical protocols

\begin{tabular}{lc}
\hline Clinical protocols & Number of protocols ongoing \\
\hline Cancer & \\
Cytokine/Immunotherapy & 64 \\
Drug resistance genes & 7 \\
Drug sensitivity genes & 26 \\
Intracellular immunization & 15 \\
Marking studies & 32 \\
Infectious diseases & 12 \\
Monogenic diseases & 25 \\
Other diseases & 3 \\
Total & 184 \\
\hline
\end{tabular}

of the molecular basis of human diseases such as cancer and inherited disorders. In this context, gene therapy offers the unique possibility of correcting diseases at their roots - the abnormal or dysregulated genes.

Despite more than a decade of intense research on human immunodeficiency virus (HIV) pathogenesis aimed at developing effective antiviral drugs and the implementation of highly active antiviral treatments, HIV infection remains an incurable and fatal disease. The mere fact that the HIV genome is integrated into the chromosomal DNA of T lymphocytes renders HIV eradication virtually impossible by conventional antiviral treatments. In addition, high rates of mutation in the viral genome and generation of drug-resistant strains of HIV are major limiting factors that prevent the development of an effective drug-based therapy. Thus, it is clear that alternative approaches to the treatment of HIV infection need to be explored.

The recognition that HIV infection is a true genetic disorder resulting from the acquisition of new genetic material via an infectious process has opened the way for the development of gene therapy strategies for HIV infection. In addition, studies of the underlying mechanisms of the viral infectious cycle and pathogenesis have provided a number of molecular targets that can be exploited in the context of gene therapy. Gene therapy may, therefore, be a novel and potentially effective way to treat HIV infections and prevent AIDS. In theory, this can be achieve in two ways: by preventing de novo infection of susceptible cells by inserting a therapeutic gene before the cell is exposed to the virus and by suppressing ongoing replication in chronically infected cells. In the past few years, a number of phase I/II human clinical protocols have been approved for a variety of diseases. A classification of these protocols is presented in Table 1. Of note, all the protocols approved so far for infectious diseases concern HIV infections.

The term 'intracellular immunization' was introduced by David Baltimore in 1988 (1) and refers to any forms of genetransfer-based cellular resistance to viral infection. In the past few years, a number of intracellular immunizationbased strategies have been evaluated for the treatment of HIV infections, some of which are now in human clinical trials. The present paper reviews the different intracellular immunization approaches that have been employed for HIV treatment.

\section{GENETIC INTERVENTIONS FOR HIV INFECTIONS}

The ultimate goal of gene therapy for HIV infection is to inhibit viral replication and prevent the occurrence of AIDS. A variety of strategies have been developed to accomplish gene therapy for HIV infection. These approaches include intracellular immunization, DNA vaccination and immunopotentiation. For each of these strategies, there is a human clinical gene therapy trial directed toward specific HIV targets. Intracellular immunization refers to the efficient and stable transfer of genetic elements that inhibit viral replication. The rationale for immunization with naked DNA plasmid (DNA vaccines) is based on the observation that exogenous DNA is taken up by antigen-presenting cells and elicits an immune response against the protein encoded by the transgene. Immunopotentiation is the modification of a host immune response by altering the specificity or effector function of immune system cells such as T lymphocytes.

Intracellular immunization: Intracellular immunization refers to any forms of gene-transfer-based cellular resistance to viral infection. In contrast with conventional immunization techniques, in which the entire organism is protected against invasion by a pathogen, intracellular immunization consists of the genetic modification of target cells to inhibit or abrogate the replication cycle of a given infectious agent, usually by competing for the binding of proteins that are essential for the replication of this agent. In this strategy, the immunizing moiety is produced inside the cells where it can bind proteins that are usually not accessible by conventional immunization techniques. Thus, the gene encoding the immunizing molecule renders cells resistant to viral gene expression and replication. Intracellular immunization can be accomplished by either protein-based or RNA-based approaches. The therapeutic molecules employed so far, in the context of HIV infection, include transactivation response (TAR) and Rev response element (RRE) decoys, antisense, catalytic RNAs, transdominant negative mutants and single-chain antibodies (sFvs). Obviously, the rationale behind the intracellular immunization strategy is to protect uninfected, susceptible cells against HIV infection. Protection of cells may thus persist longer in infected individuals and maintain a therapeutic threshold of immune function. Currents studies focus on gene transfer to mature $\mathrm{CD} 4+$ cells, mainly because of the ease of isolation and relative efficacy of transduction, while future studies will introduce antiviral genes into progenitor cells to maintain a renewable source of protected hematopoietic cells.

Protein-based approaches - sFvs: The humoral immune system is extraordinarily diverse and can form literally millions of different kinds of antibodies, each capable of binding just one of the millions of different antigens to which the body may become exposed. Antibodies, displaying high affinity binding properties, have been exploited for identification, purification and manipulation of target molecules.

An important advance in this field was the discovery that monoclonal antibodies could be produced by hybridomas, which were made by fusing a single B lymphocyte with an immortal cell line. Hybridomas can secrete unlimited quantitites of a single antibody. Recent progress in antibody engineering 
techniques has permitted the isolation of specific antigenbinding sites of immunoglobulins from hybridomas in vitro. Three technical advances in molecular biology have allowed the derivation of the antigen-binding domains of the heavy and light chains to form single-chain fragments. First, it has become possible to express the variable heavy and light chains of antibodies in Escherichia coli as single-chain fragments. Second, large repertoires of single-chain fragments can be generated by polymerase chain reaction from mRNA extracted from hybridomas and spleen. Third, efficient techniques are available to select high binding affinity single-chain fragments from repertoires that are specific for a target molecule. These advances have made possible the development of sFvs for therapeutic purposes.

A sFv is the smallest domain region of an antibody that retains the binding specificity of the parental antibody. This single molecule is constructed by linking the heavy and light variable regions using a small flexible linker (Figure 1). In contrast with regular antibodies, sFvs can be expressed intracellularly and directed to different subcellular compartments by the use of appropriate localization signals. Their ability to functionally inactivate virtually any target molecule inside a cell is clearly an advantage over regular antibodies. When expressed intracellularly, sFvs bind to their target proteins and sequester the viral proteins in an inappropriate cellular compartment such that the HIV replication cycle is disrupted. Essentially all viral proteins involved in the infectious cycle of HIV have been targeted using this approach. For example, the envelope protein mediates the attachment of the virus to its cellular receptor, and is required both for cell-free and cell-tocell transmission of the virus. An $\mathrm{sFv}$ directed against the conserved epitope of the HIV-1 envelope glycoprotein precursor, gp160, has been shown to inhibit HIV replication and cytopathic syncytium formation by blocking the surface expression of gp120 in a cell culture system (2-4). When targeted to the endoplasmic reticulum (ER) (via appropriate subcellular localization signals), the sFv directed against the HIV-1 envelope protein can bind to this molecule and trap it in the ER, thus preventing maturation of the HIV-1 envelope protein to the surface of the cell. Based on these data, a clinical gene therapy protocol was approved in 1995 by the Recombinant Advisory Committee in the United States.

Other interesting results have been obtained with sFvs targeted to Tat and Rev proteins. Tat acts as a potent transactivator of viral gene expression by activating transcription from the long terminal repeat (LTR). Studies on the effects of antiTat sFvs have demonstrated effective sequestration of Tat in the cytoplasm and blockage of its transport to the nucleus (5). Moreover, a marked inhibition of HIV-1 replication was observed in stably transfected cells $(6,7)$. The Rev protein is required for the nuclear export of a subset of HIV-1 mRNAs that encode structural proteins. Cytoplasmic sFvs directed against the C-terminus domain of Rev have demonstrated significant anti-HIV-1 activity. The sFvs abrogated Rev transport to the nucleus, and led to a sustained inhibition of virus replication (8-10). Although potent antiviral activity has been demonstrated with these sFvs, postintegration blockage of HIV-1 rep-

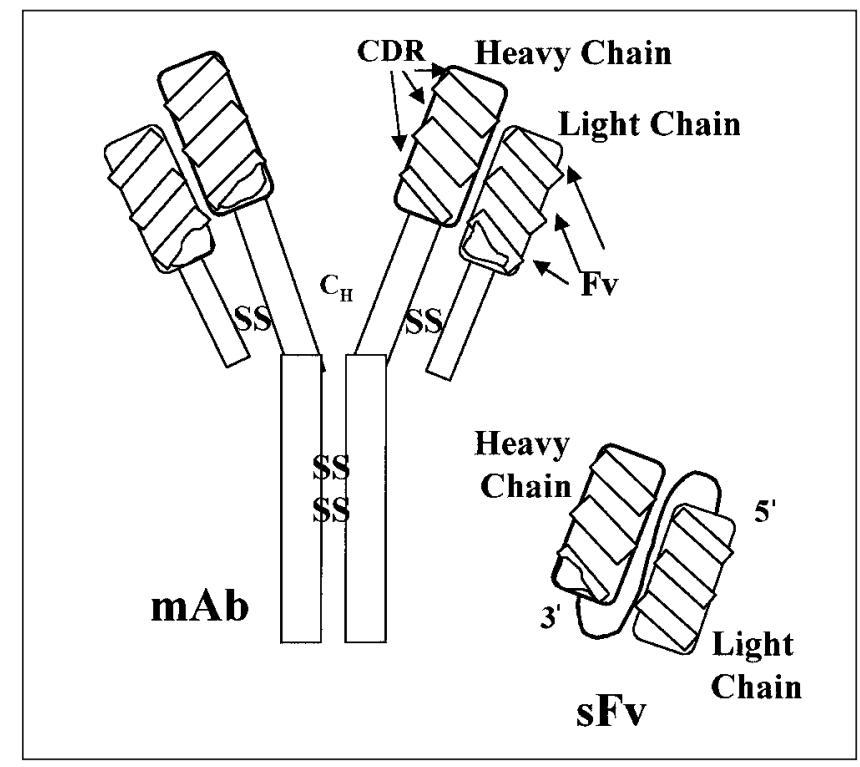

Figure 1) Structure of a monoclonal antibody and the single-chain antibody ( $S F v$ ) derived from it. The sFv is constructed by linking the variable heavy and light regions of the antibody using a small flexible peptide linker. The variable heavy and light regions are derived by polymerase chain reaction amplification. CDR Complementary determining region; Fv Framework; mAb Monoclonal antibody; $C_{H}$ Heavy chain constant region; SS Disulphide cross-links

lication does not stop the virus from integrating into uninfected cells to maintain a latent infection. A more attractive approach in this context is preintegration blockade of virus replication. Using such an approach, inhibition of HIV-1 replication has been demonstrated with sFvs directed against matrix protein (MA, p17), which is part of the preintegration complex (11), reverse transcriptase $(12,13)$ and integrase (14). However, it should be mentioned that in vivo efficacy remains to be demonstrated.

Intracellular immunization-based strategies are also being considered for AIDS-related malignancies (15). With the improvement of antiviral therapy and prophylaxis against opportunistic infections, HIV patients are now living longer. Hence, there has been a significant increase in AIDS-related malignancies in the past 10 years (16). The different gene therapy strategies for these malignancies were recently reviewed (15). Of note, sFvs have been employed in this context also. An sFv directed against the latent membrane protein 1 (LMP1) of Epstein-Barr virus has been shown to reduce LMP1 protein levels and enhance the sensitivity to chemotherapeutic drugs in Epstein-Barr virus-transformed B lymphocytes (17).

Strategies targeting cellular proteins, such as HIV-1 coreceptors, have also been recently developed. For example, CXCR-4, a transmembrane glycoprotein, is synthesized in the ER and transported to the plasma membrane, where CXCR-4 binds to its ligand (SDF-1) and interacts with the envelope protein of T-tropic HIV-1 virus. In an elegant study by Chen et al (18), T-lymphocytes were genetically modified to stably express the SDF- 1 chemokine, the natural ligand of CXCR-4. The SDF-1 molecule was modified and targeted to the ER by the addition of an ER retention signal (SEKDEL). Intracellular ex- 
pression of SDF-1 in the ER was able to block the surface expression of newly synthesized CXCR-4. This phenotypic knock-out of CXCR-4 rendered lymphocytes resistant to Ttropic HIV-1 infection. One major limitation of this strategy and the intracellular SFv approach as a whole is the need to modify genetically a large number of $\mathrm{T}$ lymphocytes to achieve significant protection. This seems difficult with the current vectors available for in vitro and in vivo gene transfer.

Capsid-targeted viral inactivation: In capsid-targeted viral inactivation, a polypeptide or protein is fused to a virionassociated component to prevent the production of infectious virions and subsequent spread to uninfected cells (19). In this context, a number of HIV-1 accessory proteins, including Vpr, Vif and Nef, are present in infectious virion, in addition to gag, pol and env gene products $(20,21)$. Vpr, together with the matrix protein, facilitates, nuclear transport of the viral preintegration complex in nondividing cells (22). A number of studies have shown that Vpr can be fused to various molecules and still be packaged into HIV particles. The successful incorporation of Vpr into HIV virions when fused to staphylococcal nuclease (23), HIV-1 protease mutant $(22,24)$ and short peptides derived from HIV-1 proteins $(25,26)$ has been demonstrated. Studies on Vpr-fusion constructs have shown an accumulation of Gag/Pol precursors and reduced infectivity of virus progeny in cells transduced with the Vpr-HIV-1 protease mutant plasmids (24), and a delay in HIV-1 replication in T cells transduced with Vpr-Vpu polypeptide (22). This is an interesting method that may contribute to the development of an effective antiviral therapy. In addition, Vpr can be fused to a variety of therapeutic molecules, including sFvs and transdominant negative mutants.

Transdominant negative mutant proteins: Transdominant negative proteins (TNPS) are mutated versions of HIV-1 proteins that can inhibit HIV-1 replication. TNPs lack wild-type activity and interfere with the normal function of their wild type protein counterpart. TPNs of both regulatory (Tat, Rev) and structural (gag, env) genes have been described (27-30). Perhaps the most investigated TNP is a mutant of Rev protein called RevM10. The RevM10 mutant still binds to the RRE but can no longer interact with a cellular cofactor that activates the Rev functions (31). A clinical trial was initiated in 1994 with RevM10 in HIV-infected patients with a CD4 count greater than 250 (31). Patients' $\mathrm{CD} 4^{+}$-enriched peripheral blood lymphocytes were transduced ex vivo with a retroviral vector encoding RevM10, re-infused in the patient, and the fate of those genetically modified $\mathrm{T}$ lymphocytes was followed over time. Persistence of the transgene was observed for several months after the reinfusion. In addition, the lymphocytes expressing RevM10 survived for significantly longer times (32). While no adverse effects was observed in the three patients tested, there were also no major changes in viral loads or $\mathrm{CD} 4$ counts. Nevertheless, these data suggest that it is possible to generate genetically modified $\mathrm{T}$ lymphocytes that are less susceptible to HIV infection in vivo.

RNA-based approaches - Ribozymes: Ribozymes are RNA molecules that have catalytic activities. They function by binding to a specific RNA target through antisense sequence and in- activate it by cleaving the phosphodiester backbone at a specific site (33). Anti-HIV ribozymes that recognize and cleave specific regions of the viral genome have been described (33). Ribozymes have the advantage of being able to cleave both incoming HIV genomic RNA and newly transcribed viral mRNA. One of the first ribozymes designed to inhibit HIV was targeted to the viral gag sequence (34). Expression of this ribozyme in HIV-1 infected cells reduced the levels of gag RNA and gag-derived proteins. Another ribozyme targeted to the 5 LTR of HIV-1 was shown to inhibit expression of diverse strains of HIV-1 in cell culture (35). In this study, multiple strains of HIV-1 were inhibited because the leader sequence, which was targeted by the ribozyme, is conserved within all HIV-1 RNA. In a subsequent study, the same ribozyme was constitutively and persistently expressed in $\mathrm{T}$ lymphocytes, and cells expressing it were shown to be resistant to challenge from various strains of HIV. In addition, the virus production was inhibited for up to 35 days after the challenge (36). One potent limitation of the ribozyme approach is the propensity for escape mutants to emerge because a single nucleotide change at a critical position of the target sequence can lead to resistance to the ribozyme cleavage. In an attempt to overcome this potential problem, multiribozymes containing vectors have been tested $(36,37)$. The approach was based on the idea that targeting different sites in the viral RNA should decrease the risk of viral escape. Simultaneous expression of two distinct ribozymes (U5 ribozyme, Rev ribozyme) and a RNA decoy (stem loop II) has resulted in efficient and sustained inhibition of different virus clades, whereas a single ribozyme or decoy-ribozyme vector allowed breakthrough replication of some clades (37). As with previously described strategies, it is necessary to transduce a large number of Tymphocytes if this strategy is to be efficient in HIV-infected patients. This might be difficult to achieve in the context of the high turnover rates of $\mathrm{T}$ lymphocytes in HIV-infected patients $(38,39)$. A clinical trial is currently underway with an anti-HIV-1 ribozyme to test its safety and efficacy (33).

Antisense RNA: Antisense RNA molecules (ASs) have been widely used for intracellular immunization. They use the specificity of Watson-Crick base pairing to block gene expression in a specific manner. Therapeutic ASs have be used in two forms: short oligonucleotides (15 to 20 acid bases long) and expressed nucleotides (few dozen bases to several thousands). Stable intracellular expression is the most efficient method whereby ASs can be used to inhibit HIV-1 gene expression. In this strategy, the AS molecule is cloned into a retroviral vector and transfected into the target cell. The expressed AS RNA transcripts can then bind to a specific HIV DNA region and inhibit viral transcription. In a recent comparative study, intracellularly expressed AS complementary to various genes of HIV-1 were evaluated (40). The most efficient inhibition of HIV-1 replication was observed with an env AS, leading to 2 to $3 \log _{10}$ reductions in p24 antigen production (a measure of viral activity in the supernatant).

RNA decoys: This strategy consists of sequestering nucleic acid-binding viral regulatory proteins by overexpressing short RNA molecules that compete with viral RNAs for binding of 
these proteins. The TAR and RRE are examples of such viral regulatory elements. Retroviral-mediated gene transfer of TAR and RRE decoys resulted in marked inhibition of viral replication in vitro (41-43). Although it is clear that TAR and RRE are effective against HIV, they only affect a postintegrative step, and thus this approach would not prevent latent infection.

\section{CONCLUSIONS}

A wide variety of gene therapy strategies have been developed that can achieve the significant inhibition of HIV replication in Tlymphocytes in vitro, and some of these strategies are now being tested in human clinical trials. It is hoped that these clinical trials will determine whether intracellular immunization or other gene therapy approaches have potential clinical applications in combination with conventional antiviral treatments.

One of the major technical difficulties with the intracellular immunization approach is to transduce stably enough mature T lymphocytes to obtain a clinical benefit. This is true particularly in the context of the rapid turnover of $\mathrm{T}$ lymphocytes

\section{REFERENCES}

1. Baltimore D. Gene therapy: intracellular immunization. Nature 1988;335:395-6.

2. Chen SY, Bagley J, Marasco WA. Intracellular antibodies as a new class of therapeutic molecules for gene therapy. Hum Gene Ther 1994;5:595-601.

3. Marasco WA, Haseltine WA, Chen SY. Design, intracellular expression, and activity of a human anti-human immunodeficiency virus type 1 gp120 single-chain antibody. Proc Natl Acad Sci USA 1993;90:7889-93.

4. Chen SY, Khouri Y, Bagley J, Marasco WA. Combined intra- and extracellular immunization against human immunodeficiency virus type 1 infection with a human anti-gp120 antibody. Proc Natl Acad Sci USA 1994;91:5932-6.

5. Mhashilkar AM, Bagley J, Chen SY, Szilvay AM, Helland DG, Marasco WA. Inhibition of HIV-1 Tat-mediated LTR transactivation and HIV-1 infection by anti-Tat single chain intrabodies. EMBO J 1995;14:1542-51.

6. Poznansky MC, Foxcall U, Ramstedt R, et al. Intracellular antibodies against Tat and gp120 inhibit the replication of HIV-1 in T-cells from HIV-infected individuals. Hum Gene Ther 1998;9:487-96.

7. Mhashilkar AM, Biswas DK, LaVecchio J, Pardee AB, Marasco WA. Inhibition of human immunodeficiency virus type 1 replication in vitro by a novel combination of anti-Tat single-chain intrabodies and NF-B antagonists. J Virol 1997;71:6486-94.

8. Duan L, Bagasra O, Lauglin MA, Oakes JW, Pomerantz RJ. Potent inhibition of human immunodeficiency virus type 1 replication by an intracellular anti-Rev single-chain antibody. Proc Natl Acad Sci USA 1994;91:5075-9.

9. Duan L, Zhu M, Bagasra O, Pomerantz RJ. Intracellular immunization against HIV-1 infection of human T lymphocytes: utility of anti-rev single-chain variable fragments. Hum Gene Ther 1995;6:1561-73.

10. Wu Y, Duan L, Zhu M, et al. Binding of intracellular anti-Rev single-chain variable fragments to different epitopes of human immunodeficiency virus type $1 \mathrm{rev}$ : variations in viral inhibition. J Virol 1996;70:3290-7.

11. Levin R, Mhashilkar AM, Dorfman T, et al. Inhibition of early and late events of the HIV-1 replication cycle by cytoplasmic Fab intrabodies against the matrix protein, p17. Mol Med 1997;3:96-110.

12. Shaheen F, Duan L, Zhu M, Bagasra O, Pomerantz R. Targeting human immunodeficiency virus type 1 reverse transcriptase by (half-life of about $6 \mathrm{~h}$ ) in HIV-infected patients. Moreover, in addition to $\mathrm{CD} 4+$ lymphocytes in peripheral blood, a large number of proviral-harbouring cells are located in lymphoid tissue throughout the body (44), cells which may be hard to reach with the approaches discussed above. Because of these limitations, stem cell gene therapy for AIDS is being investigated and offers several potential advantages $(45,46)$. Because HIV primarily infects hematopoietic cells, intracellular immunization of hematopoietic stem cells is particularly attractive. In addition, transduction of even a small fraction of hematopoietic stem cells may lead to the expansion of a significant population of cells resistant to HIV infection.

Gene therapy offers not only the possibility of controlling disease but also eradication of the viral genome in order to cure the infection. More studies are needed to define the therapeutic potential of gene therapy, and there is no doubt that clinicians will hear more about gene therapy for HIV in the next few years.

ACKNOWLEDGEMENTS: I thank Drs Pierre Bourgaux and Raymond Duperval for their helpful comments.

intracellular expression of single-chain variable fragments to inhibit early stages of the viral life cycle. J Virol 1996;70:3392-400.

13. Maciejewski JP, Weichold F, Young NS, et al. Intracellular expression of antibody fragments directed against HIV reverse transcriptase prevents HIV infection in vitro. Nat Med 1995;1:667-73.

14. Levy-Mintz P, Duan L, Zhang H, et al. Intracellular expression of single-chain variable fragments to inhibit early stages of the viral life cycle by targeting human immunodeficiency virus type 1 integrase. J Virol 1996;70:8821-32.

15. Curiel TJ, Piché A, Kasono K, Curiel DT. Gene therapy strategies for AIDS-related malignancies. Gene Ther 1997;4:1284-8.

16. Gail MH, Pluda JM, Rabkin CS, et al. Projections of the incidence of non-Hodgkin's lymphoma related to acquired immunodeficiency syndrome. J Natl Cancer Inst 1991;83:695-701.

17. Piché A, Kasono K, Johanning F, Curiel TJ, Curiel DT. Phenotypic knock-out of the latent membrane protein 1 of Epstein-Barr virus by an intracellular single-chain antibody. Gene Ther 1998;5:1171-9.

18. Chen JD, Bai X, Yang AG, Cong Y, Chen SY. Inactivation of HIV-1 chemokine co-receptor CXCR-4 by a novel intrakine strategy. Nat Med 1997;3:1110-6.

19. Cohen EA, Dehni G, Sodroski JG, Haseltine WA. Human immunodeficiency virus vpr product is a virion-associated regulatory protein. J Virol 1990;64:3097-9.

20. Yuan X, Matsuda Z, Matsuda M, Essex M, Lee TH. Human immunodeficiency virus vpr gene encodes a virion-associated protein. AIDS Res Hum Retroviruses 1990;6:1265-71.

21. Liu H, Wu X, Newman M, Hahn BH, Kappes JC. The vif protein of human and simian immunodeficiency viruses is packaged into virions and associates with viral core structures. J Virol 1995;69:7630-8.

22. Heinzinger NK, Bukinsky MI, Haggerty SA, et al. The Vpr protein of human immunodeficiency virus type 1 influences nuclear localization of viral nucleic acids in nodividing host cells. Proc Natl Acad Sci USA 1994;91:7311-5.

23. $\mathrm{Wu} \mathrm{X}$, Liu $\mathrm{H}$, Xiao $\mathrm{H}$, et al. Targeting foreign proteins to human immunodeficiency virus particles via fusion with Vpr and Vpx. J Virol 1995;69:3389-98.

24. Wu X, Liu H, Xiao H, Conway JA, Kappes JC. Inhibition of human and simian immunodeficiency virus protease function by 
targeting Vpx-protease-mutant fusion protein into viral particles. J Virol 1996;70:3378-84.

25. Kobinger GP, Borsetti A, Nie Z, et al. Virion-targeted viral inactivation of human immunodeficiency virus type 1 by using Vpr fusion protiens. J Virol 1998;72:5441-8.

26. Serio D, Riziv TA, Cartas M, et al. Development of a novel anti-HIV-1 agent from within: effect of chimeric Vpr-containing protease cleavage site residues on virus replication. Proc Natl Acad Sci USA 1997;94:3346-51.

27. Malim MH, Freimuth WW, Liu J, et al. Stable expression of transdominant rev prtoein in human $\mathrm{T}$ cells inhibits human immunodeficiency virus replication. J Exp Med 1992;176:1197-201.

28. Liem SE, Ramezani A, Li X, Joshi S. The development and testing of retroviral vectors expressing trans-dominant mutants of HIV-1 proteins to confer anti-HIV-1 resistance. Hum Gene Ther 1993;4:625-34.

29. Trono D, Feinberg MB, Baltimore D. HIV-1 gag mutants dominantly interfere with the replication of the wild-type virus. Cell 1989;59:113-20.

30. Buschschacher GL Jr, Freed EO, Panganiban AT. Cells induced to express a human immunodeficiency virus type 1 envelope gene mutant inhibit the spread of wild-type virus. Hum Gene Ther 1992;3:391-7.

31. Nabel GJ, Fox BA, Post L, Thompson CB, Woffendin C. A molecular genetic intervention for AIDS - effects of a transdominant negative form of Rev. Hum Gene Ther 1994:5:79-92.

32. Ranga U, Woffendin C, Verma S, et al. Enhanced T cells engraftment after retroviral delivery of an antiviral gene in HIV-infected individuals. Proc Natl Acad Sci USA 1998:95:1201-6.

33. Bunnell BA, Morgan RA. Gene therapy for AIDS. Mol Cell 1996;1:1-12.

34. Sarver N, Cantin EM, Chang PS, et al. Ribozymes as potential anti-HIV-1 therapeutic agents. Science 1990;247:1222-5.

35. Yu M, Ojwang J, Yamada O, et al. A hairpin ribozyme inhibits expression of diverse strains of human immunodeficiency virus type 1. Proc Natl Acad Sci USA 1993;90:6340-4.
36. Yamada O, Kraus G, Luznik L, Yu M, Wong-Staal F. A chimeric human immunodeficiency virus type 1 (HIV-1) minimal Rev response element-Ribozyme molecule exhibits dual antiviral function and inhibits cell-cell transmission of HIV-1. J Virol 1996;70:1596-601.

37. Gervaix A, Li X, Kraus G, Wong-Staal F. Multigene antiviral vectors inhibit diverse human immunodeficiency virus type 1 clades. J Virol 1997;71:3048-53.

38. Ho DD, Neumann AU, Perelson AS, Chen W, Leonard JM, Markowitz M. Rapid turnover of plasma virions and CD4 lymphocytes in HIV-1 infection. Nature 1995;373:123-6.

39. Wei X, Ghosh SK, Taylor ME, et al. Viral dynamics in human immunodeficiency virus type 1. Nature 1995;373:117-22.

40. Veres G, Junker U, Baker J, et al. Comparative analyses of intracellularly expressed antisense RNAs as inhibitors of human immunodeficiency virus type 1 replication. J Virol 1998; 72:1894-901.

41. Sullenger BA, Gallardo HF, Ungers GE, Gilboa E. Overexpression of TAR sequences render cells resistant to human immunodeficiency virus replication. Cell 1990;63:601-8.

42. Sullenger BA, Gallardo HF, Ungers GE, Gilboa E. Analysis of trans-acting response decoy RNA-mediated inhibition of human immunodeficiency virus type 1 transactivation. J Virol $1991 ; 65 ; 6811-6$

43. Lee TC, Sullinger BA, Gallardo HF, et al. Overexpression of RRE-derived sequences inhibits HIV-replication in CEM cells. New Biol 1992;4:66-74.

44. Pantaleo G, Graziosi C, Demarest JF, et al. HIV infection is active and progressive in lymphoid tissue during the clinically latent stage of disease. Nature 1993;362:355-8.

45. Rosenzweig M, Marks DF, Hempel D, Lisziewicz J, Johnson RP. Transduction of CD34+ hematopoietic progenitor cells with an antitat gene protects T-cell and macrophage progeny from AIDS-virus infection. J Virol 1997;71:2740-6.

46. Joshi S, Ramezani A, Medina MM, et al. RNA and protein based strategies for use in anti-HIV gene therapy. 6th Annual Canadian conference on HIV/AIDS Research. Can J Infect Dis 1997;8:61A. (Abst 407) 


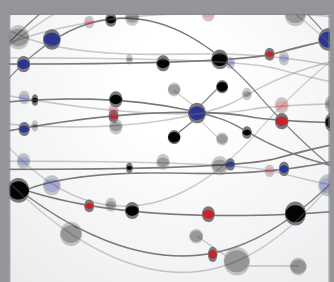

The Scientific World Journal
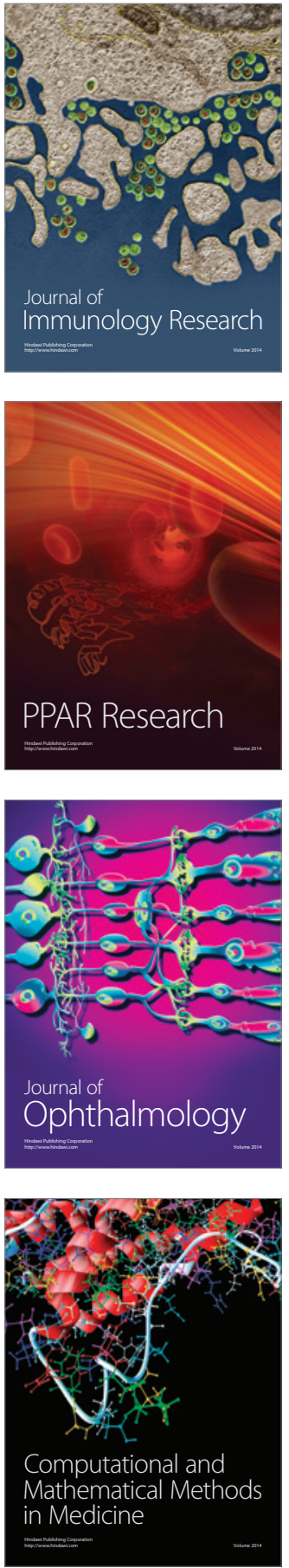

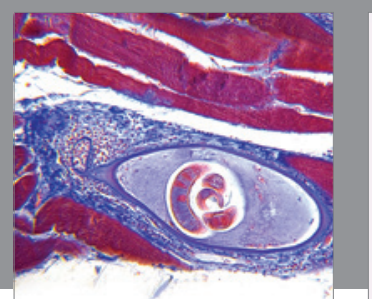

Gastroenterology Research and Practice

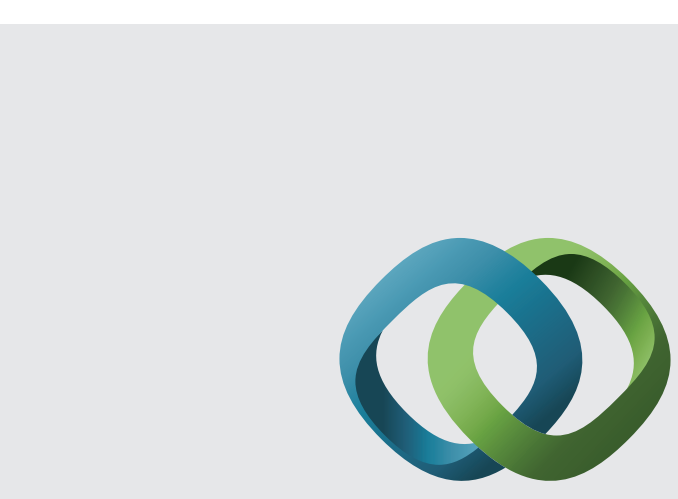

\section{Hindawi}

Submit your manuscripts at

http://www.hindawi.com
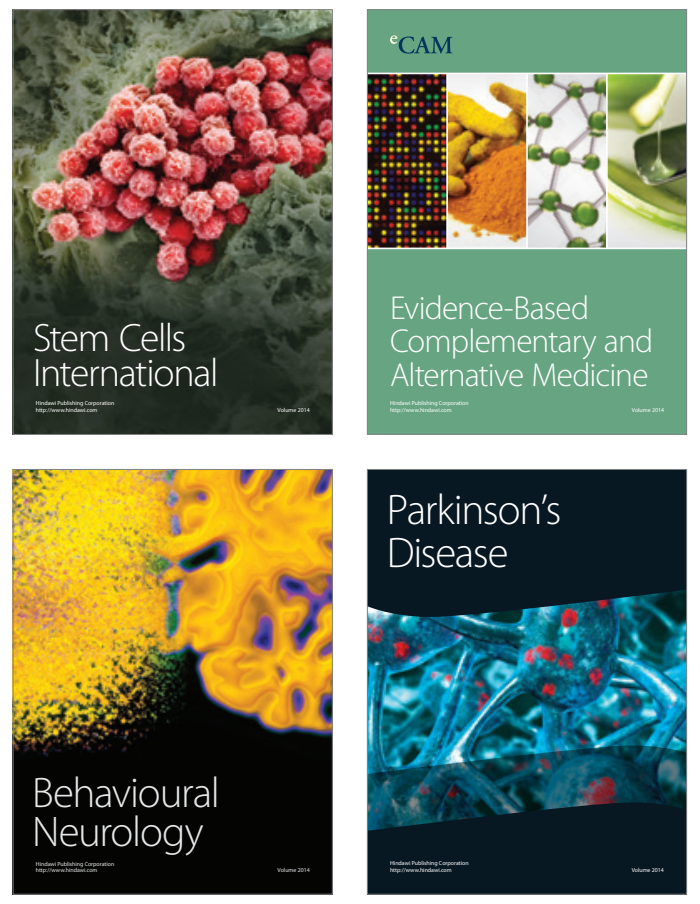
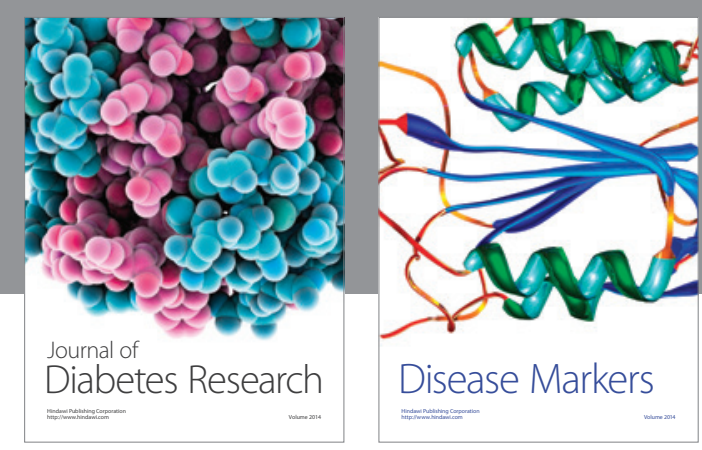

Disease Markers
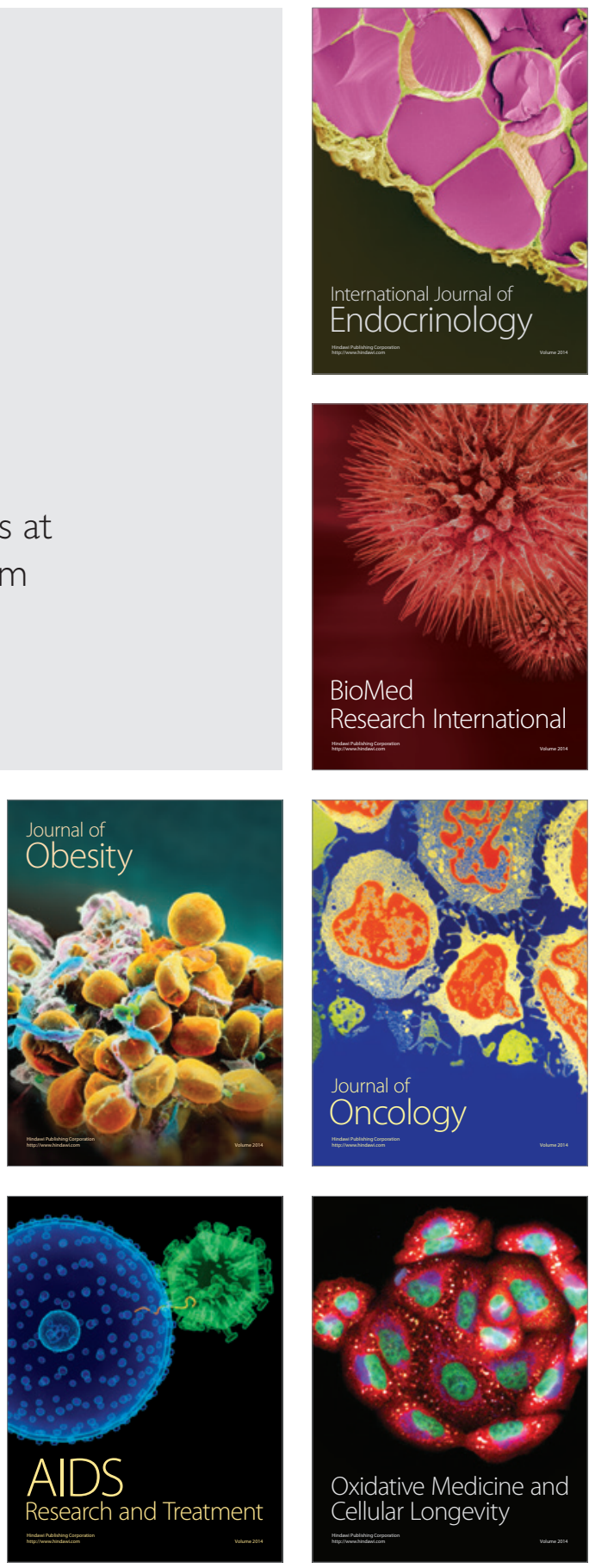